\title{
Modeling, Characterization and linearization of Negative Temperature Coefficient (NTC) Thermistor and Pressure Sensors
}

\author{
K. Narayana Swamy, Nandeesh M, Nagaraj Hediyal
}

\begin{abstract}
Industrial applications such as air-conditioning, microelectronic, automotive, food processing are automated using various sensor technologies. The sensor technologies could be temperature, pressure and others as well. The negative temperature coefficient (NTC) sensors are the preferred choice due to their stability over their counterpart positive temperature coefficient (PTC) sensors. These sensors are highly nonlinear and need special signal conditioning circuits to use them in all industrial applications. Pressure sensor does need a special treatment while measuring their values for industrial applications. This paper presents the method to model, characterize and linearize NTC and pressure sensors. A low-cost system was built to validate the presented method.
\end{abstract}

Index Terms: Temperature, NTC/PTC, Coefficient, Modeling, Characterization, Linearization, pressure sensor.

\section{INTRODUCTION}

$\mathrm{T}$ emperature measurements are very critical and essential in air-conditioning, food processing and other industrial applications. Generally, these industrial applications make use of negative or positive temperature (NTC/PTC) coefficient Thermistor as temperature detectors/sensors. NTC Thermistor are preferred choice even though less sensitive than their counterparts due to their stability. Thermistor possesses unique thermoelectric properties which makes them to be suitable for temperature detectors in many applications [1].

The accurate measurement of temperature is a challenge in aeronautical, food processing and other applications as these NTC sensors are highly nonlinear. Therefore, these sensors need special treatment to use them in various industries to detect temperature [2]. There are many technologies based on which NTC sensors are manufactured. Mainly the oxide concentration ratio defines the characteristics of these sensors. Metal oxide sensors have higher sensitivity compared to other sensors.

Revised Manuscript Received on March 5, 2020.

K Narayan Swamy*, Associate Professor, School of EEE,REVA UNIVERSITY, Bengaluru, India. E-mail: knarayanswamy@reva.edu.in

Nandeesh M,M.Tech student,REVA UNIVERSITY Bengaluru, India Nagaraj Hediyal,CEO,eNLiven Technologies,Bengaluru,India. E-mail: Nagaraj_hediyal@yahoo.com
The stability and reliability of these sensors are high [3].During the manufacturing process, the thermal treatment applied to coat either glass or epoxy to complete the sensor product. The coating material such as Aerosol Deposited NiMn2O4 plays an important role, while forming the leads of the sensor. The influence of this coating agent has the direct impact on the temperature detection and ageing [4]. The linearization method for these sensors is the major criteria due to their inherent characteristics of nonlinearity. An error evaluation associated with resistive linearization circuits has been proposed in [5]. The proposed method utilizes a resistive linearization technique using voltage source. The results of the proposed method were compared with other methods for analyses. The analysis shows that the results of practical implementation compared with those of thermotical have huge difference. Meaning the practical implementations does have error in results which need special attention [5].

A series and parallel resistive divider network along with two stage piecewise linear analog to digital converter (PWC ADC) has been presented to linearize the NTC Thermistor in [6]. Method was intended to improve the accuracy of NTC by reducing the nonlinearity. The accuracy of measurement completely relies on the resolution of the $1^{\text {st }}$ stage ADC. The measurement error greatly reduces if and only if $1^{\text {st }}$ stage ADC resolution is higher. Another way of linearizing the NTC sensors is by way of gain linearization and is presented in [7]. The simulation and experimental results were compared to validate the gain linearization method. The method was tested for the range of temperature between $3000^{\circ} \mathrm{K}$ to $3720^{\circ} \mathrm{K}$. A full Wheatstone bridge with differential amplifier has been presented [8] to measure the low pressure for wireless biomedical applications. The paper presents the analysis of low magnitude signal conditioning and how the noise affects the pressure measurements if improper ADC selected for the purpose of pressure measurement. A frame work on Thermistor temperature transducer to ADC application has been presented in [9] The application report deals with the measurement of low magnitude signal and the error issues. The paper presents the generic method of treating the low magnitude sensor signals while interfacing with the microcontrollers/processors. Generally, the low magnitude signals are dealt with ratio metric measurement methods where in the scope is extended to self-calibration [10]. The accuracy in most of the measurement systems is guaranteed by way of reference signal. 
These references will have changes based upon the quantity such as voltage, current to be measured [11]. It has been established that the reference voltage has an influence on the measurement accuracy that need to be taken care. The selfcalibration is another way of assuring the accuracy of measurement of any sensor output signal [12]. The ratio metric measurements with self-calibration techniques play an important role in the measurement accuracy.

By considering the results of the various researchers' presentation introduced above, a ratio metric conversionbased approach has been considered in this paper to model, characterize and linearize temperature and pressures sensors. The rest of the paper is described section wise; section 2 describes the modeling of NTC and Pressure Sensors, $3^{\text {rd }}$ section describes the proposed model \& technique, $4^{\text {th }}$ section describes the results and analysis and $5^{\text {th }}$ section presents the conclusion.

\section{MODELING OF NTC AND PRESSURE SENSORS}

Since NTC sensors are thermally sensitive resistors with negative temperature coefficient, a best fitting model to determine change in resistance is proposed by Steinhart and Hart. The mathematical expression proposed by Steinhart and Hart is:

$$
T=\frac{1}{A+B \ln (R)+C[\ln (R)]^{3}}
$$

Where:

$\mathrm{T}$ is temperature in degrees Kelvin and $\ln (\mathrm{R})$ is the natural $\log$ of the measured resistance of the sensor; and A, B and C are constants (i.e., $\mathrm{A}=1.874 \mathrm{E}-03, \mathrm{~B}=2.3573 \mathrm{E}-04$ and $\mathrm{C}=9.5052 \mathrm{E}-08$ ). The values of coefficients $\mathrm{A}, \mathrm{B}$ and $\mathrm{C}$ corresponding to TR141 series NTC sensors.

These values may vary depending on the type of the sensor considered for the application. Accuracy is the important factor in the acquisition of temperature of NTC sensors. The accuracy depends upon the method of excitation i.e, constant voltage or constant current source.

An NTC sensor of $5 \mathrm{~K} @ 25^{\circ} \mathrm{C} \quad$ (TR141 series) is considered for the experimental purpose. The temperature sensor TR141 is shown in Fig. 1.

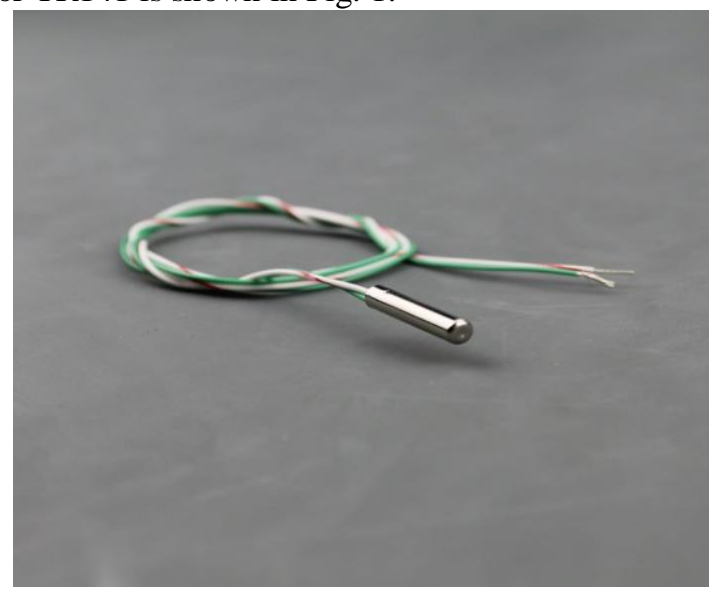

Fig. 1. TR141 @ $\mathbf{2 5}^{\circ} \mathrm{C}$

The temperature verses resistance curve of the NTC sensor is shown in Fig. 2.

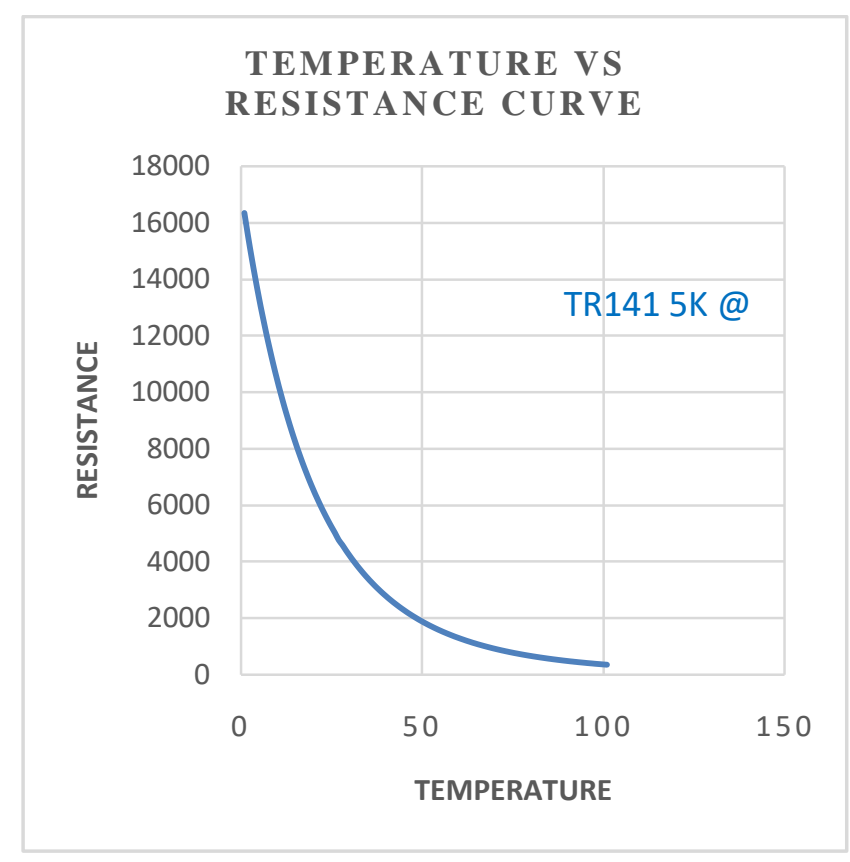

Fig. 2. Temperature Vs Resistance of NTC Sensor TR141 with 5K @ $25^{\circ} \mathrm{C}$.

The NTC temperature sensor is highly non-linear as seen from Fig. 2. This need to be linearizes to acquire the temperature.

Proceeding further, industrial automation uses pressure sensors extensively. The range of pressure measured in airconditioning applications is $0-10$ bar or $0-40$ bar. In industrial applications, the excitation voltage used for the pressure sensors is about $24 \mathrm{~V}$ DC. This pressure sensor transmitter provides an analog signal proportional to the pressure applied to the sensor. The 0-10 bar pressure sensor from Danfoss MBS3000 series is considered and the variation of pressure verses signal is shown in Fig. 3 and Fig. 4.

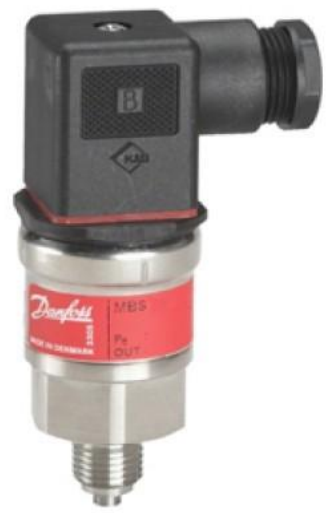

Fig. 3. Pressure Transmitter 


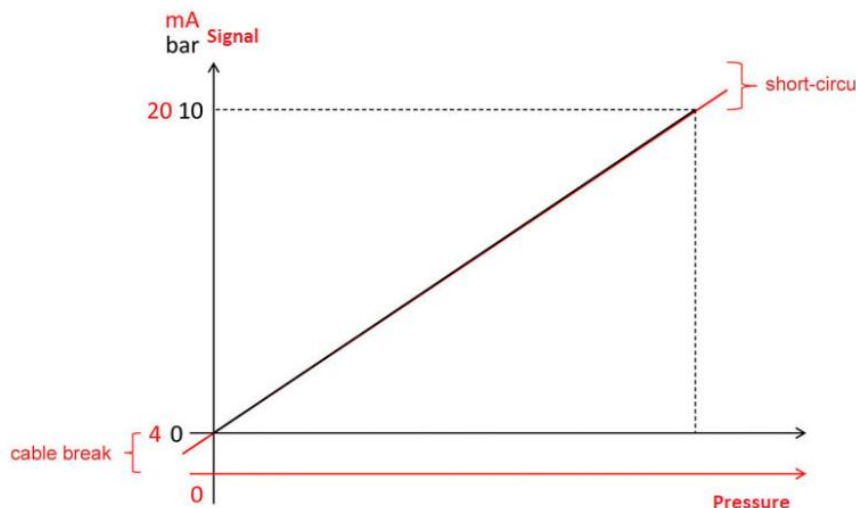

Fig. 4. Pressure verses signal (Bar/mA)

\section{PROPOSED LINEARIZATION \&CHARACTERIZATION TECHNIQUES FOR NTC TEMPERATURE AND PRESSURE SENSORS}

A voltage divider circuit is generally preferred to linearize the NTC sensors and is presented in Fig. 5.

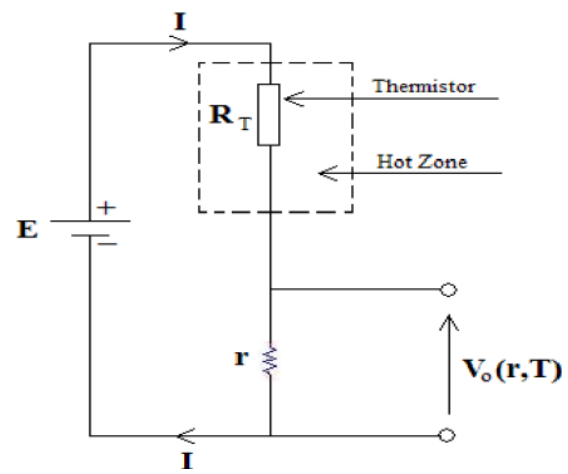

Fig. 5. Voltage divider circuit to linearize NTC

Resistor $R_{T}$ is the NTC sensor and resistor ' $r$ ' is the series resistor across which voltage $\mathrm{V}_{\mathrm{o}}$ corresponding to that resistance is obtained when the excitation voltage source ' $E$ ' is enabled [6]. This method has a major disadvantage of being nonlinear due to both parameters' variation in drop across series resistor ' $\mathrm{r}$ ' and $\mathrm{R}_{\mathrm{T}}$. Therefore, a series and parallel voltage divider circuit is considered to improve the linearity and shown in Fig. 6.

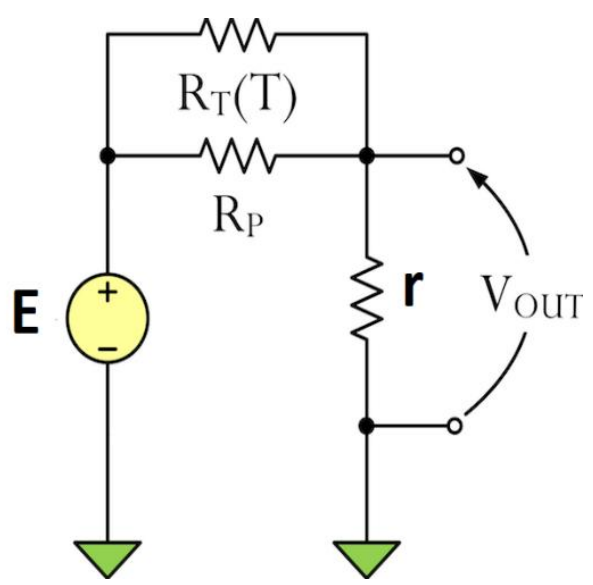

Fig. 6. Series Parallel Voltage divider circuit [6]

In this method also the excitation source is voltage source which eventually produces error in the measurement of resistance of NTC. This results in the temperature measurement error.
In this paper a constant current excitation method with series parallel resistive voltage divider circuit is proposed with certain considerations:

i) Desired range of temperature $\left(0^{\circ} \mathrm{C}-100^{\circ} \mathrm{C}\right)$ with a sensor of TR141@25․

ii) The value of $R_{P}$ in parallel with $R_{T}$ (NTC) is chosen such that the voltage drop developed across this parallel combination prevents saturation of the constant current source.

iii)The voltage drop developed across the parallel combination must be in accordance with the analog to digital converter (ADC) input range and the resolution requirement to ensure the accuracy of the measurement.

iv)The series resistance ' $r$ ' is selected based on the reference voltage required during measurement by a transducer circuit proposed in this paper.

v) The resistance of the NTC sensor at $0^{\circ} \mathrm{C}$ is $16330 \Omega$ and $339.6 \Omega$ at $100^{\circ} \mathrm{C}$.

The proposed constant current source excitation series parallel resistive divider circuit is shown in Fig. 7 .

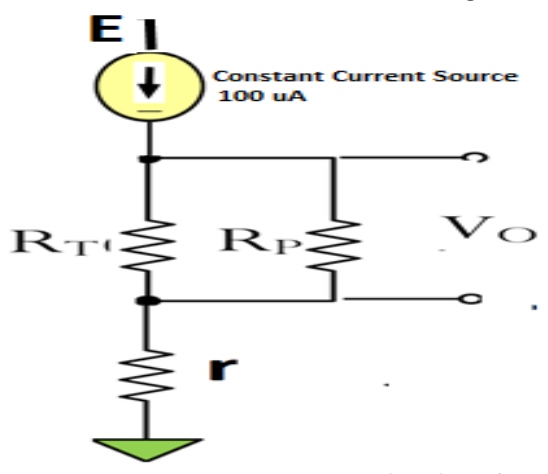

Fig. 7. Constant current source excitation for series parallel Voltage divider circuit

The constant current source of $100 \mu \mathrm{A}$ is used in the proposed linearization technique to avoid:

i) Self-heating of NTC sensor.

ii) Electromagnetic interference (EMI) problem.

iii) Noise problem and

iv) To limit the range of drop (across parallel combination of NTC and $\mathrm{R}_{\mathrm{P}}$ ) to the ADC reference voltage.

This arrangement is next interfaced with a transducer block whose output is used to determine the NTC resistance at any point of time to determine temperature using a Steinhart \& Hart equation presented in preceding sections. The block diagram of the transducer used in the proposed technique is shown in Fig. 8. 


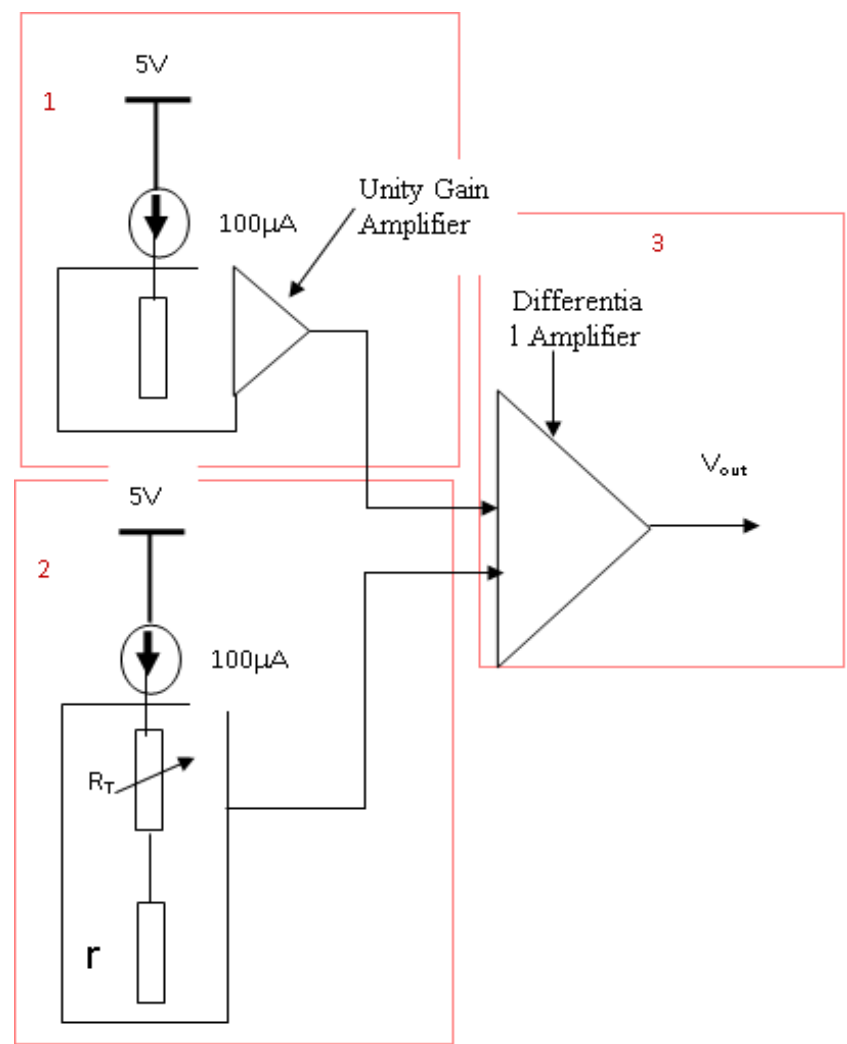

Fig. 8. Block Diagram of the proposed Technique

The block diagram has three sections; $1^{\text {st }}$ section deals with the generation of reference voltage, where in another additional constant current source of $100 \mu \mathrm{A}$ (Mirror image of constant current source used for excitation of NTC sensor) has been used. This reference voltage plays an important role in the measurement of change in resistance of NTC sensor as the temperature changes. The reference voltage is created by using a reference resistor $\left(R_{F}\right)$ in section 1 along with a constant current source as mentioned above. Thus, generated reference voltage is buffered using a unity gain amplifier to avoid the loading effect at the output of the transducer.

Section 1 has a linearization circuit built with series \& parallel voltage divider circuit shown in Fig. 7. The series resistance ' $r$ ' is used to force the higher reference voltage to ease the measurement of voltage across the parallel combination of $R_{T}$ and $R_{P}$ by reducing the noise level. The output voltage $\mathrm{V}_{\mathrm{O}}$ is passed through a low pass filter (Not shown in block diagram) to eliminate the local noise due to devices present within the circuitry.

Section 3 has a differential amplifier fed with the output from both section 1 and 2. This section also has a capacitor at the feedback circuit to eliminate the high frequency signals interfering with the temperature signal generated from section 2. Also, a low pass filter to eliminate local noise signal. The output signal $\mathrm{V}_{\text {out }}$ is then fed to the ADC of 10-bit resolution.

The gain of the differential amplifier designed within the section 3 of the transducer is given by:

$G=\frac{V_{\text {out } \text {, } \max }-V_{\text {out }, \min }}{I_{s}\left(R_{T 0}-R_{T 100}\right)}$

Where:

$\mathrm{G}$ is gain of the differential amplifier, Vout ${ }_{\max }$ is maximum allowable voltage input to $\mathrm{ADC}, \mathrm{Vout}_{\min }$ is minimum allowable voltage input to ADC, $\mathrm{I}_{\mathrm{S}}$ is current fed to NTC sensor in $\mu \mathrm{A}, \mathrm{R}_{\mathrm{T} 0}$ is resistance at $0^{\circ} \mathrm{C}$ and $\mathrm{R}_{\mathrm{T} 100}$ is resistance at $100^{\circ} \mathrm{C}$.

As per the data sheet of NTC 5k @ $25^{\circ} \mathrm{C}$, the resistance of the sensor considered in the proposed technique has: $16330 \Omega @ 0{ }^{\circ} \mathrm{C}$ and $339.6 \Omega @ 100^{\circ} \mathrm{C}$.

To linearize the NTC sensor, a parallel resistance $R_{P}=16330 \Omega$ has been chosen according to the point number 2 in section 3i.e the maximum drop across the parallel combination $R_{T} \| R_{P}$ has to be equal to reference voltage of the ADC. Hence, the gain of the differential amplifier of the proposed transducer is computed by using equation (2) as $\mathrm{G}=6$.

The reference voltage in section 1 is determined using:

$G=\frac{V_{r e f}-V_{r}-V_{\text {out }, \mathrm{min}}}{R_{T 100} I_{s}}$

Where:

$V_{\text {ref }}$ is reference voltage of the unity gain amplifier in section 1 and $V_{\mathrm{r}}$ is drop across series resistance at section 2 .

The reference voltage is determined using equation (3) with all the parameter values substituted as $0.499 \mathrm{~V}$.

The output of the transducer shown in Fig. 8 is fed to a 10-bit ADC of microcontroller to determine the resistance of the NTC sensor at various temperatures at different times. The results obtained from this proposed technique are presented in section 4 of this paper.

Next, the pressure sensor transmitter signal is $4-20 \mathrm{~mA}$. This signal is preferred to eliminate the noise, EMI issues and more importantly the drop of the cable used to transmit the data. The typical $4-20 \mathrm{~mA}$ transceiver connectivity is as shown in Fig. 9.

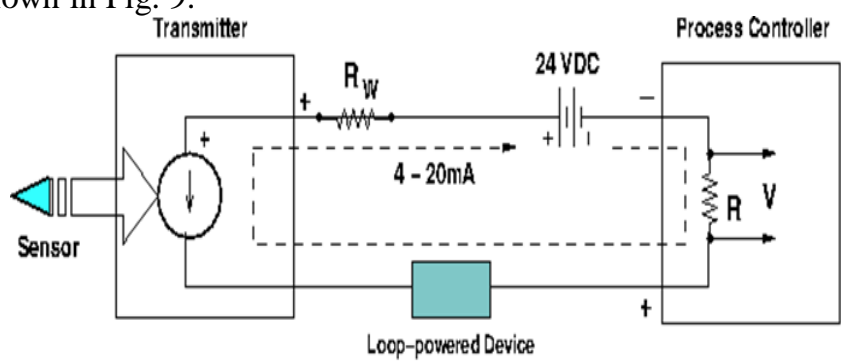

Fig. 9. 4-20mA Transceiver loop

According to the data sheet of the pressure sensor selected the supply voltage varies from $10-30 \mathrm{~V}$ DC. Generally, in industry $24 \mathrm{~V}$ DC supply is the preferred to excite the pressure sensor with 4-20mA loop.

Since the maximum load that can be connected to receive 4-20mA signal when the pressure sensor selected (Danfoss MBS3000) used for the application is given by:

$R_{L} \leq \frac{V_{s}-10}{0.02}$

Where:

$R_{L}$ is maximum allowable load resistance at the receiver and $V_{s}$ is Supply voltage i.e., $24 \mathrm{~V}$ DC

The $\mathrm{R}_{\mathrm{L}}$ is computed as less than or equal to $700 \Omega$ by using above equation

The proposed signal conditioning circuit block for the pressure sensor is shown in Fig. 10. 


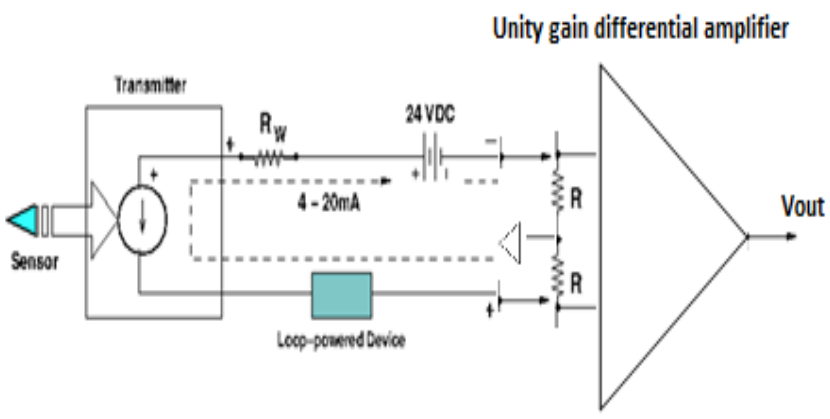

Fig. 10: Signal conditioning circuit for pressure sensor

Though the maximum allowable load resistance at the 4$20 \mathrm{~mA}$ signal receiver is $700 \Omega$, but practically the selection of this resistance depends upon the reference voltage of the corresponding ADC used to measure pressure. Since the $\mathrm{ADC}$ used is of 10-bit resolution with a maximum reference voltage of $5 \mathrm{~V}$, the load resistance has to be determined accordingly. The maximum current is $20 \mathrm{~mA}$ and hence the upper limit of the load resistance to be used at the $4-20 \mathrm{~mA}$ receiver input circuit computed as $250 \Omega\left(R_{L}=5 /\left(20 \times 10^{-3}\right)\right.$

Now, with this value of load resistance the minimum and maximum input voltage to the ADC are determined as $1 \mathrm{~V}$ and $5 \mathrm{~V}$ respectively.

In order to prevent the voltage becoming higher than the desired values at the ADC input, the load resistance is divided into two half sections with the intermediate point is connected to local ground as shown in Fig. 10.

As seen from the Fig. 4 in section 2, the pressure verses 4-20mA current signal or bar resembles a straight line as defined by an equation:

$y=m x+c$

Where:

This is a two-pint approximation technique used to determine the pressure with the signal conditioning circuit proposed in Fig. 10. Assuming the pressure along ' $y$ ' axis and current along ' $x$ ' axis, the slope ' $m$ ' and constant ' $c$ ' are determined by:

$m=\frac{y_{2}-y_{1}}{x_{2}-x_{1}}$

(6)

And

$c=y(x)-m x$

Since the pressure to be measured is 0 to $10 \mathrm{bar}$ and the corresponding currents are $4-20 \mathrm{~mA}$, the slope of the twopoint approximation

Hence the pressure can be directly determined using the following relation:

$y=0.625 x-2.5$

Now with these proposed techniques, the temperature and pressure are acquired and the results are presented in section 4. The experimental model was designed and developed to validate the proposed techniques. The experimental set up is shown in Fig. 11 (a) \& (b).
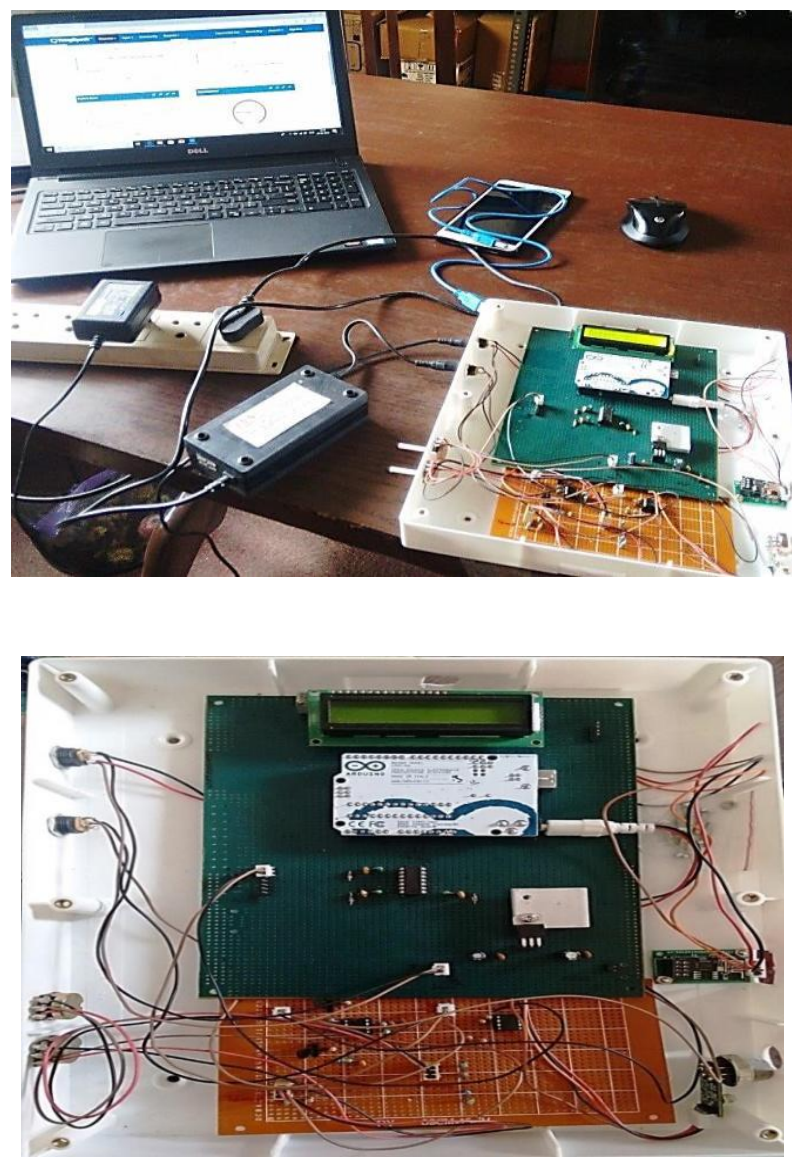

Fig. 11 (a \& b). Experimental setup

IV. RESULTS AND ANALYSIS

Experimental results obtained for NTC sensor are shown in Fig. 12 where the variation of resistance verses temperature with and without linearization resistance are plotted.

\section{RESISTACES VS TEMPERATURE}

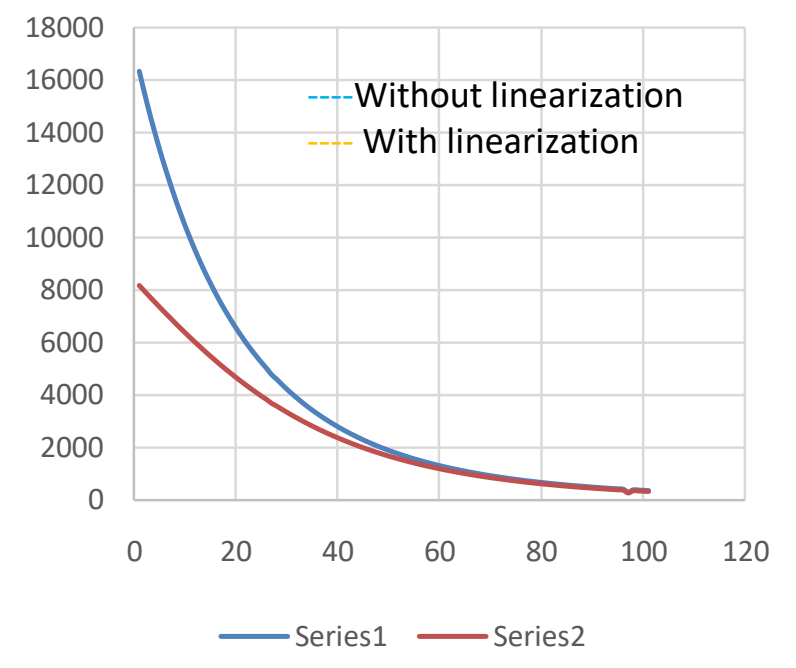

Figure 12: Resistance verses Temperature (with and without linearization resistance) 
From the Fig. 12 it is clear that the proposed technique linearize the NTC sensor to a greater extent compared to without linearization resistance. The curve resistance verses temperature with parallel resistance is much linear than that without it. The experimental results of temperature acquisition using Steinhart \& hart equation with the proposed transducer have been tabulated in Table I.

\section{TABLE I}

Comparison TABle Of NTC SEnSor

\begin{tabular}{|c|c|c|c|c|}
\hline $\mathrm{R} 1$ & $\begin{array}{c}\mathrm{R} \\
\text { PARALL } \\
\text { EL }\end{array}$ & R EQIVALENT & $\begin{array}{l}\text { R Steinhart } \\
\text { \& Hart }\end{array}$ & $\%$ Error \\
\hline 16330 & 16330 & 8165 & 8162 & 0.03 \\
\hline 9951 & 16330 & 6183.167688 & 6184.1 & 0.009323123 \\
\hline 7857 & 16330 & 5304.701286 & 5306.01 & 0.013087142 \\
\hline 6247 & 16330 & 4518.470567 & 4521.2 & 0.027294326 \\
\hline 5000 & 16330 & 3827.941866 & 3831.78 & 0.038381341 \\
\hline 4029 & 16330 & 3231.670023 & 3238.65 & 0.069799769 \\
\hline 3266 & 16330 & 2721.666667 & 2723.13 & 0.014633333 \\
\hline 2663 & 16330 & 2289.621966 & 2293.02 & 0.03398034 \\
\hline 2184 & 16330 & 1926.364913 & 1927.98 & 0.01615087 \\
\hline 1801 & 16330 & 1622.101925 & 1689.01 & 0.669080751 \\
\hline 1493 & 16330 & 1367.93413 & 1360.54 & 0.073941301 \\
\hline 1244 & 16330 & 1155.941732 & 1158.34 & 0.023982679 \\
\hline 1041 & 16330 & 978.6155086 & 990.05 & 0.114344914 \\
\hline 875.7 & 16330 & 831.1304393 & 831.12 & 0.000104393 \\
\hline 740 & 16330 & 707.9203281 & 702.89 & 0.050303281 \\
\hline 628.1 & 16330 & 604.836214 & 608.08 & 0.03243786 \\
\hline 535.4 & 16330 & 518.4034769 & 521.04 & 0.026365231 \\
\hline 458.2 & 16330 & 445.6943568 & 448.28 & 0.025856432 \\
\hline 393.7 & 16330 & 384.4317346 & 388.31 & 0.038782654 \\
\hline 339.6 & 16330 & 332.6815281 & 334.87 & 0.021884719 \\
\hline
\end{tabular}

From Table I it is clear that the percentage of error in measurement of change in NTC sensor resistance due to change in temperature is very minimal. Hence the proposed method can be used in various industrial applications.

Similarly, the experimental results of the pressure sensor are tabulated in Table II.

TABLE I

Pressure Measurement Results

\begin{tabular}{|c|c|c|c|}
\hline $\mathrm{x}$ & $\mathrm{c}$ & $\mathrm{y}=0.625 * \mathrm{x}-2.5$ & Measured $(\mathrm{y})$ \\
\hline 4 & -2.5 & 0 & 0 \\
\hline 5 & -2.5 & 0.625 & 0.61 \\
\hline 6 & -2.5 & 1.25 & 1.3 \\
\hline 7 & -2.5 & 1.875 & 1.7 \\
\hline 8 & -2.5 & 2.5 & 2.6 \\
\hline 10 & -2.5 & 3.75 & 3.55 \\
\hline 15 & -2.5 & 6.875 & 6.98 \\
\hline 20 & -2.5 & 10 & 10.01 \\
\hline
\end{tabular}

From Table II it is clear that the two point approximation technique can be used to determine the pressure from a 4$20 \mathrm{~mA}$ loop. The last column of the table 2 shows the pressure measured using microcontroller with ADC of 10- bit resolution and has a values approximately same as those obtained using mathematical model.

\section{CONCLUSION}

Modeling, characterization and linearization of both NTC and Pressure sensors have been presented in this paper. The experimental and mathematical model values of both sensors approximately close enough to indicate that the proposed techniques are indeed produce better results. The experimental setup has been designed and developed to verify the values obtained using mathematical models with those of experimental values and are in close agreement with each other. The hardware model was very compact and the technique can still be improved with linearization improvement. The percentage of error in determining the change in resistance of NTC sensor using series and parallel voltage divider circuit excited by constant current source is the better solution as it results in less percentage of error as shown in Table I.

\section{ACKNOWLEDGMENT}

The authors wish to thank management of REVA University and $\mathrm{M} / \mathrm{s}$ eNLiven Technologies for providing the facilities to carry out the research work, experimental studies and publish this work.

\section{REFERENCES}

1. Shweta Jagtap, Sunit Rane and Suresh Gosavi, "Synthesis, Characterization and Fabrication of "NTC Thick Film Thermistor Using Lead Free Glass Frit",Journal of Materials Science and Engineering A 6 (11-12) (2016) 301-309 doi: 10.17265/2161 6213/2016.11-12.003.

2. F. C. S. Luz, S. A. Pianaro, C. E. Yurk, G. Capobianco, A. J. Zara, S. M. Tebcherani, "Construction and testing of a system for the electrical characterization of ceramic thermistors at low temperatures",Cerâmica 60 (2014) 96-101.

3. Obrad S. Aleksić, Pantelija M. Nikolić, "Recent Advances In NTC Thick Film Thermistor Properties And Applications",FACTA UNIVERSITATIS Series: Electronics and Energetics Vol. 30, No 3, September 2017, pp. 267 - 284 DOI: 10.2298/FUEE1703267A.

4. Michaela Schubert, Christian Münch, Sophie Schuurman, VéroniquePoulain ,Jaroslaw Kita and Ralf Moos, "Thermal Treatment of Aerosol Deposited NiMn2O4 NTC Thermistors for Improved Aging Stability", Sensors 2018, 18, 3982; doi:10.3390/s18113982 www.mdpi.com/journal/sensors.

5. Daniel Slomovitz and José Joskowicz, "Error evaluation circuits of thermistor linearizing",Meas. Sci. Technol. 1 (1990) 1280-1284. Printed in the UK.

6. Jelena Lukić, Dragan Denić, “A Novel Design Of An NTC Thermistor Linearization Circuit," Metrology And Measurement Systems Index 330930, ISSN 0860-8229 www.metrology.pg.gda.plMetrol. Meas. Syst., Vol. XXII (2015), No. 3, pp. 351-362

7. Sinha U. K, "Op-Amp Based Inverting Amplifier for Gain Linearization of NTC Thermistor Characteristics", International Journal of Recent Scientific Research Vol. 9, Issue, 5(E), pp. 26836 26839, May, 2018

8. J.Sosa,JuanA.MontielNelson,R. Pulido, and Jose C. GarciaMontesdeoca, "Design and Optimization of a Low Power Pressure Sensor for Wireless Biomedical Applications”Hindawi Publishing Corporation Journal of Sensors Volume 2015, Article ID 352036, 13 pages http://dx.doi.org/10.1155/2015/352036.

9. John Bishop, "Thermistor Temperature Transducer to ADC Application" Application Note SLOA052-September 2000, Texas Instruments. 
10. White paper on "Voltage Measurement Accuracy, Self-Calibration and Ratiometric Measurements", CAMPBELL SCIENTIFIC, INC.

11. Russell Anderson, "Understanding ratio metric Conversions", Application Report SBAA110-March 2004

12. Eric Jacobsen and Jeff Baum, "The ABC of Signal-Conditioning Amplifier Design for Sensor Applications", Application Note AN1525, Rev 1, 05/2005, Freescale Semiconductor

\section{AUTHOR PROFILE}

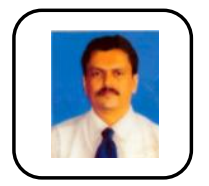

K.Narayana Swamy received the B.E. degree in Electrical Power from Mysore, India in 1986 and received the M.E. degree in Power Systems from Bangalore, India in 1994 and perusing Ph.D degree in Power Electronics from Kuvempu University, India. He worked as Lecture and Senior lecturer in the Electronics and Communication Engineering department of S.J.C. Institute of Technology, Chickballapur, India from 1987-2001. He later joined Sri Venkateshwara College of Engineering, Bangalore, India as Assistant Professor from 2001-2008. Then he joined REVA ITM, Bangalore, India as Professor in 2009 and presently working as Associate Professor in REVA University. He is pursuing his Ph.D in the area of multilevel inverter.

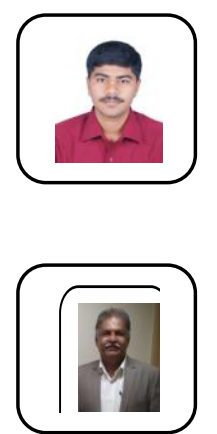

Nandeesh M. received the B.E. degree in Electrical and Electronics Engineering from Bangalore, India in 2017 and received the M.Tech. degree in Power Electronics from Bangalore 30 years of experience in Research and Development in the field of Cryptography, Embedded, VLSI, Communication, HVAC controllers, Power Electronics and Renewable Energy. He has authored and coauthored more than 38 proprietary encryption algorithms and successfully implemented them in the defense network. He is actively involved in designing, creating and managing specialized systems in the area of secure communications, Avionics, Industrial Electronics, Renewable Energy sectors. $\mathrm{He}$ is also actively involved in academics, teaching advanced subjects such as FPGA design Methodologies, Embedded System Design, Digital Signal Processing, Microprocessors \& Microcontrollers for M.Tech, and M Sc (Electronics). 